\title{
Apoptose, Proliferação e Histomorfometria do Baço de Ratas Adultas com Hipofunção Tireoidiana e Ovariana
}

\begin{abstract}
RESUMO
Apoptose, proliferação e histomorfometria do baço foram investigados em ratas Wistar adultas ovariectomizadas e não-ovariectomizadas, mantidas em hipotireoidismo induzido pela administração diária de propiltiouracil (PTU) por 120 dias. Dois grupos eutireóideos ovariectomizados e não-ovariectomizados serviram como controle. Foi colhido o plasma para dosagem de T4 livre e o baço para análise da histomorfometria, do índice apoptótico e da expressão imunohistoquímica de caspase 3 e CDC47. Valores de T4 livre foram menores nas ratas tratadas com PTU $(p<0,05)$. Nos grupos hipotireóideos houve redução do peso do baço, do número e do tamanho dos folículos linfóides e aumento do índice apoptótico e da expressão de caspase $3(\mathrm{p}<0,05)$. Porém, o baço de ratas hipotireóideas ovariectomizadas apresentou aumento menos acentuado do índice apoptótico e da expressão de caspase 3 do que o baço de ratas hipotireóideas não-ovariectomizadas ( $p<0,05)$. O grupo eutireóideo ovariectomizado apresentou hiperplasia da polpa branca em relação ao grupo eutireóideo não-ovariectomizado. Não houve diferença na expressão de CDC47 entre os grupos. Conclui-se que a hipofunção tireoidiana e gonadal apresentam efeitos distintos no baço e que na associação hipotireoidismo-hipogonadismo há aumento menos acentuado do índice apoptótico e da expressão de caspase-3 esplênica do que no hipotireoidismo isolado. (Arq Bras Endocrinol Metab 2008; 52/6:1031-1038)
\end{abstract}

Descritores: Hipotireoidismo; Castração; Baço; Rata

\section{ABSTRACT}

Apoptosis, Proliferation and Spleen Histomorphometry of Adult Female Rats with Thyroid and Ovarian Hypofunction.

Apoptosis, proliferation and histomorphometry of spleen were investigated in ovariectomized and non-ovariectomized adult Wistar rats maintained in hypothyroidism induced by daily administration of propylthiouracil (PTU) during 120 days. Two groups ovariectomized euthyroid and non-ovariectomized euthyroid were used as controls. Plasma was collected for free T4 dosage and the spleen for histomorphometry analysis, apoptosis index and the immunohistochemistry expression of caspase 3 and CDC47. Values of free T4 were lower in rats treated with PTU $(p<0.05)$. In the hypothyroid groups there was some decrease in the spleen weight as well as the number and size of lymphoid follicles and there was some increase in the apoptotic index and the caspase 3 expression $(p<0.05)$. However, the increase in the apoptosis index and the expression of caspase 3 in ovariectomized hypothyroid rats spleen was less accentuated than non-ovariectomized hypothyroid ones $(p<0.05)$. The ovariectomized euthyroid group presented white pulp hyperplasia in comparison to the non-ovariectomized euthyroid group. There was no difference in the CDC47 expression between groups. It was concluded that the thyroid and ovarian hypofunction have distinct effects on the spleen and that in the hypothyroidism-hypogonadism association, the increase in the apoptosis index and in the expression of splenic caspase 3 is not as much as in isolated hypothyroidism. (Arq Bras Endocrinol Metab 2008; 52/6:1031-1038)

Keywords: Hypothyroidism; Castration; Spleen; Rat original

\author{
Mardelene G. Gomes \\ Cristiana Moreira da SILVA \\ Ana F. CARVAlHo Ribeiro \\ Natália M. Ocarino \\ LUCIANA MORO \\ Anilton C. VAsconcelos \\ ROGÉRIA SERAKIDES
}

Setor de Patologia do

Departamento de Clínica e Cirurgia Veterinárias da Universidade Federal de Minas Gerais (UFMG), Belo Horizonte, $M G$, Brasil.

Recebido em 4/4/2008

Aceito em 18/6/2008 


\section{INTRODUÇÃO}

$\mathrm{O}$ HIPOTIREOIDISMO TEM sido freqüentemente diagnosticado em mulheres durante a menopausa (1). Por isso, foi realizada uma sucessão de estudos, a fim de verificar o efeito da deficiência dos hormônios tireoidianos e sexuais no organismo. O estudo da inter-relação entre os hormônios tireoidianos e sexuais femininos em tecidos, como a pele, o osso e o sangue, tem demonstrado que a deficiência conjunta pode agravar ou minimizar os efeitos da deficiência isolada de cada um deles dependendo do tipo de tecido (2-5).

Os hormônios tireoidianos participam em diversos processos fisiológicos, como diferenciação e desenvolvimento celular, exercendo efeito direto sobre o metabolismo. Os hormônios tireoidianos participam como reguladores obrigatórios e estimuladores da linfopoese $\mathrm{B}$ primária (6-7) e são requeridos para a produção normal das células- $\beta$ na medula óssea, pelo controle da proliferação das células pró- $\beta$. Esses hormônios também estimulam a síntese de nucleoproteínas, com conseqüente aumento do número das células- $\beta$, principalmente no baço e na medula óssea (8).

Os esteróides sexuais, por sua vez, são inibidores da produção de linfócitos e afetam o processo de imunorregulação $(9,10)$. Os estrógenos modulam múltiplos aspectos do sistema imune e têm efeitos que dependem da dose e do tipo celular específico em que atuam (11), sendo reguladores negativos da proliferação e da função dos linfócitos T (12). A progesterona, por sua vez, exerce efeito no processo de seleção tímica, antagonizando a apoptose induzida por glicocorticóides (13).

Não obstante ter conhecimento de que ratas castradas apresentam aumento do número de linfócitos imaturos no timo, com conseqüente aumento periférico das células T e B (14), o efeito da inter-relação entre hipotireoidismo e hipogonadismo nos órgãos linfóides não é conhecido. O objetivo do presente trabalho foi estudar a apoptose, a proliferação e a histomorfometria do baço de ratas hipotireóideas ovariectomizadas e nãoovariectomizadas.

\section{MÉTODOS}

Foram utilizadas 40 ratas Wistar com três meses de idade, alojadas em caixas plásticas, na densidade de cinco ratas por caixa, que receberam ração comercial e água ad libitum, e foram mantidas em regime de 12 horas de luz e 12 horas de escuro.
A metade dos animais foi ovariectomizada e, uma semana após a ovariectomia, em dois grupos de dez ratas, um ovariectomizado e outro não-ovariectomizado, foi induzido o hipotireoidismo pela administração diária de propiltiouracil. A droga foi administrada na dose de $1 \mathrm{mg}$ /animal, diluída em $5 \mathrm{ml}$ de água destilada, por sonda gástrica. As ratas mantidas em estado eutireóideo receberam $5 \mathrm{ml}$ de água destilada, como placebo, nas mesmas condições. Assim, foram formados quatro grupos experimentais: hipotireóideo ovariectomizado $(\mathrm{n}=10)$, hipotireóideo não-ovariectomizado $(\mathrm{n}=10)$, eutireóideo ovariectomizado $(\mathrm{n}=10)$ e eutireóideo não-ovariectomizado (controle) $(\mathrm{n}=10)$.

Ao final do período experimental (120 dias), as ratas foram pesadas e sacrificadas por punção cardíaca precedida por anestesia com pentobarbital sódico 2,5\% $(30 \mathrm{mg} / \mathrm{kg})$, por via intraperitoneal. À necropsia, o baço foi coletado, pesado, fixado em formalina a $10 \%$, neutra e tamponada, e processado pela técnica rotineira de inclusão em parafina.

A razão entre o peso do baço e o peso corporal foi estabelecida. A dosagem plasmática de tiroxina livre foi realizada pela técnica de quimioluminescência (Access Immunoassay System, Sanofi Diagnostics Pasteur Inc., Chaska, MN, USA) em sistema totalmente automático e de acordo com as recomendações do fabricante dos kits. Os coeficientes de variação intra e interensaio foram de $4 \%$ e $7 \%$, respectivamente.

As secções de baço de $4 \mu \mathrm{m}$, retiradas sempre do centro do órgão, foram coradas pelas técnicas de hematoxilina e eosina, para avaliação histomorfométrica, e pelo tricrômico de Shorr, que proporcionou melhor contraste entre núcleo e citoplasma, para determinação do índice apoptótico (15).

Em secções histológicas, foi determinada a porcentagem de polpa vermelha, de polpa branca e de estroma por campo, com auxílio de retícula ocular micrométrica com 121 pontos, sob objetiva de $40 \times$. Foram avaliados 21 campos em toda a extensão da secção histológica. Além disso, o número de folículos linfóides também foi quantificado. Somente foram quantificados os folículos que apresentassem arteríola central com centro germinativo. Com uma ocular contendo régua, foi mensurado o diâmetro maior e menor dos folículos quantificados, obtendo-se o diâmetro médio folicular. No final, com auxílio de lâmina micrométrica, os dados do diâmetro dos folículos foram transformados para $\mu \mathrm{m}$.

A atividade proliferativa e a apoptose foram avaliadas pelo estudo imunohistoquímico com a utilização 
do anticorpo anti-CDC47 Clone 47DCl41 e do anticorpo anti-caspase-3 Clone RB-1197-P (NeoMarkers, Dako, Califórnia, EUA), respectivamente. As secções foram submetidas à técnica de estreptavidina-biotinaperoxidase (Ultravision large volume detection system anti-polyvalent, HRP, Lab Vision, Freemont, Califórnia, EUA), sendo empregada a técnica de recuperação antigênica pela utilização de solução Retrieval (Dako, Califórnia, EUA), durante 20 minutos. As lâminas foram incubadas em câmara úmida por uma hora com cada anticorpo primário separadamente (CDC47 - diluição de 1:200 ou caspase 3 - 1:300) (Novocastra Laboratories, Newcastle Upon Tyne, United Kingdom, Inglaterra) e por 15 minutos nas etapas de bloqueio da peroxidase endógena, soro de bloqueio (Lab Vision, Freemont, Califórnia, EUA), anticorpo secundário (Biotin Goat, Lab Vision, Freemont, Califórnia, EUA) e estreptavidina-biotina-peroxidase. Utilizou-se o DAB (Lab Vision, Freemont, Califórnia, EUA) como cromógeno, em incubação por dez minutos e a hematoxilina de Harris como contracoloração.

A quantificação do índice apoptótico e da porcentagem de células/campo com expressão de CDC47 e de caspase 3 foi realizada em imagens microscópicas obtidas com objetiva de imersão (Zeiss axiolab, Zeiss, Sachsen, Thüringen, Alemanha), capturadas por placa digitalizadora computadorizada (MicroMOVIE PRO; Sachsen, Thüringen, Alemanha) (16), as quais foram transferidas para o analisador de imagens (Programa KS300, versão 2.0, Kontron Elektronik, Sachsen, Thüringen, Alemanha) e submetidas à contagem celular.

O índice apoptótico foi determinado pela porcentagem de células com características de apoptose em relação ao número total de células em cada campo analisado. A análise foi realizada por um único observador que considerou como critério de inclusão a presença de, pelo menos, três características morfológicas peculiares do processo apoptótico: retração e perda de aderência celular, condensação do citoplasma e do núcleo e formação dos corpos apoptóticos (17).

O número mínimo de campos para determinação do índice apoptótico foi determinado pela técnica de estudo da variação da instabilidade de valores médios em relação à amostra que os originou. Em uma lâmina representativa de cada grupo experimental foi determinado o índice apoptótico em 50 campos. A seguir, a amostra de 50 campos foi dividida em cinco com valores sorteados ao acaso. Foram determinados a média, o desvio-padrão e o coeficiente de variação da variável estudada em $5,10,15$,
$20,25,30,35,40,45$ e 50 campos. Após verificar que o desvio-padrão e o coeficiente de variação se estabilizavam em torno de 30 campos, este valor foi adotado para se determinar o índice apoptótico médio em cada grupo (18). Para a análise da porcentagem de células com expressão de $\mathrm{CDC} 47$ e de caspase 3 em relação ao número total de células/campo, avaliaram-se 20 campos que abrangiam toda a área de um folículo linfóide, escolhido aleatoriamente. Consideraram-se positivas as células que apresentavam a marcação acastanhada característica do cromógeno utilizado.

O delineamento experimental foi inteiramente ao acaso com quatro tratamentos e dez repetições, sendo cada animal uma repetição. Para cada variável estudada, foram determinadas a média e o desvio-padrão. Os dados foram submetidos à análise de variância ANOVA do programa estatístico Instat (GraphPad Software, versão 3.00, 32 Win 95/NT, 1997) e as médias foram comparadas pelo teste Student-Newman-Keuls (SNK) (18). As diferenças foram consideradas significativas se $\mathrm{p}<0,05$.

\section{RESULTADOS}

As concentrações plasmáticas de T4 livre significativamente menores nos grupos tratados com propiltiouracil confirmaram a indução do hipotireoidismo, após 120 dias da administração ininterrupta deste antitireoidiano (Figura 1).

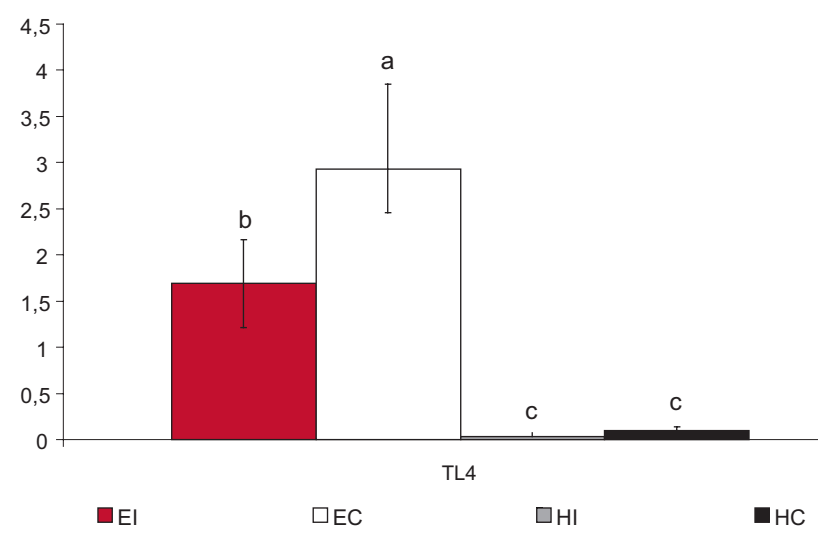

* Letras diferentes representam diferenças significativas $(p<0,05)$.

Figura 1. Concentrações plasmáticas de tiroxina livre $(\mu \mathrm{g} / \mathrm{dl})$ (média \pm SD) de ratas adultas eutireóideas ovariectomizadas (EO), eutireóideas não-ovariectomizadas (El), hipotireóideas ovariectomizadas $(\mathrm{HO})$ e hipotireóideas não-ovariectomizadas $(H I)$. 
A razão peso do baço/peso corporal foi significativamente menor nos grupos hipotireóideos em comparação aos grupos eutireóideo não-ovariectomizado (controle) e eutireóideo ovariectomizado (Figura 2).

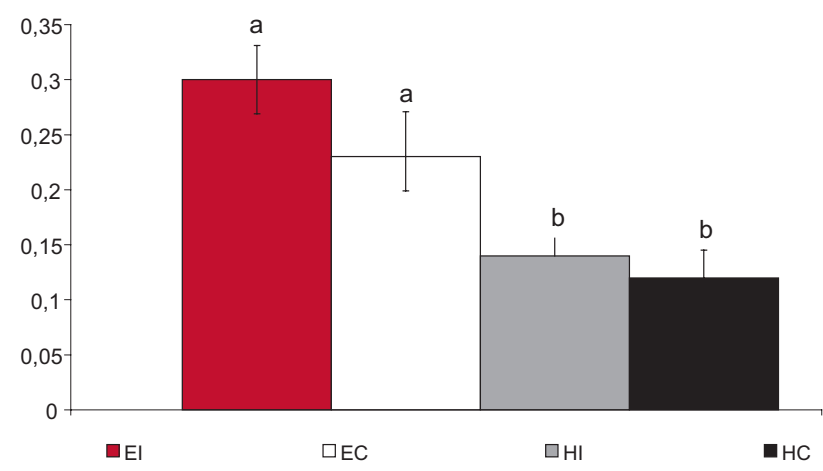

* Letras diferentes representam diferenças significativas $(p<0,05)$

Figura 2. Razão entre peso do baço (g) e peso corporal (g) (média $\pm \mathrm{SD}$ ) de ratas adultas eutireóideas ovariectomizadas (EO), eutireóideas não-ovariectomizadas (El), hipotireóideas ovariectomizadas $(\mathrm{HO})$ e hipotireóideas nãoovariectomizadas (HI).
O grupo-controle apresentou morfologia compatível com a normalidade. A polpa vermelha apresentava todos os elementos, como hemácias, linfócitos, megacariócitos e macrófagos repletos de pigmento amarronzado (hemossiderina). Na polpa branca, os folículos linfóides eram bem delimitados, de tamanho variado e alguns com centro germinativo ativo, nos quais as células, às vezes, assemelhavam-se a linfoblastos, apresentando núcleos de cromatina frouxa e citoplasma volumoso. Nos grupos hipotireóideos, ovariectomizados e nãoovariectomizados houve aparente redução de polpa vermelha e branca, contudo não houve diferença estatística significativa na porcentagem destes elementos. Embora a porcentagem de polpa branca nestes grupos não tenha diferido significativamente do grupo-controle (Figura 3 ), os folículos linfóides da polpa branca eram menores e em menor número (Figura 4) e apresentavam marcante redução da celularidade em comparação ao grupo-controle. Os linfócitos apresentavam-se diminuídos de tamanho e com núcleos intensamente basofilicos, de cromatina condensada e picnóticos. Havia também grande quantidade de células fragmentadas, principalmente na região dos centros germinativos.

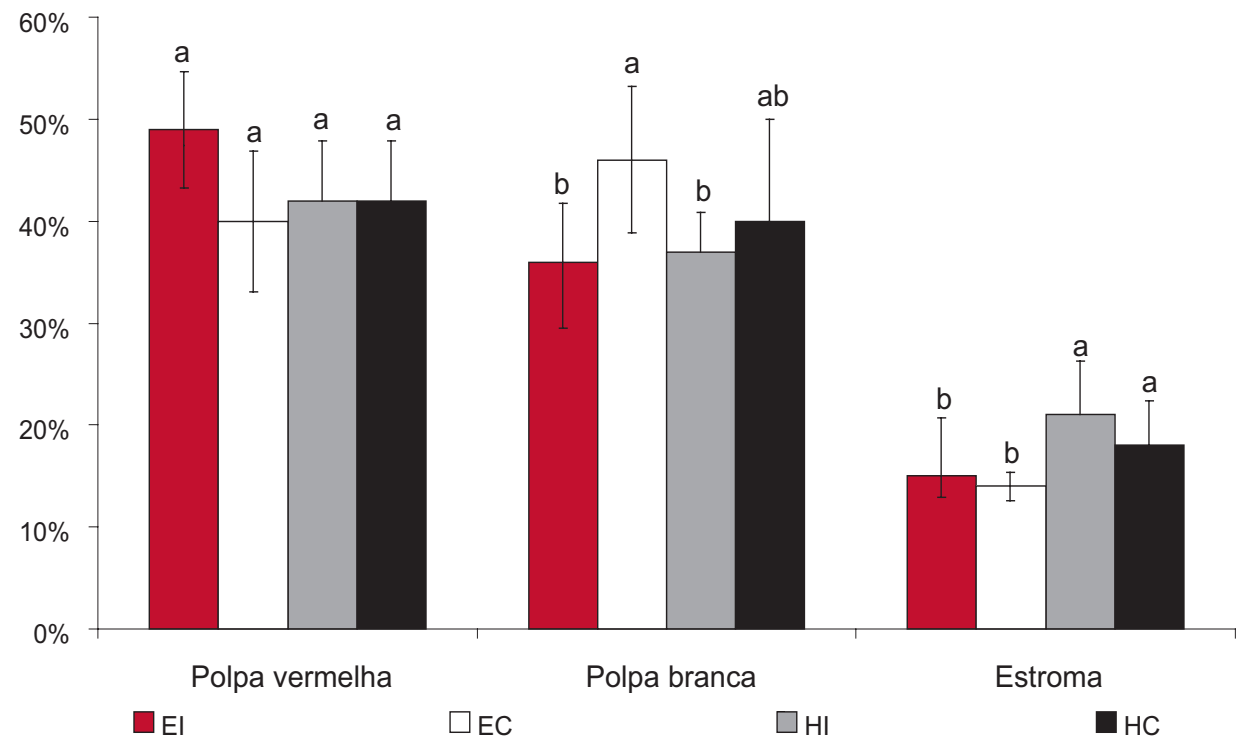

* Letras diferentes representam diferenças significativas $(p<0,05)$.

Figura 3. Porcentagem de polpas vermelha e branca e de estroma (média \pm SD) do baço de ratas adultas eutireóideas ovariectomizadas (EO), eutireóideas não-ovariectomizadas (El), hipotireóideas ovariectomizadas $(\mathrm{HO})$ e hipotireóideas não-ovariectomizadas (HI) 


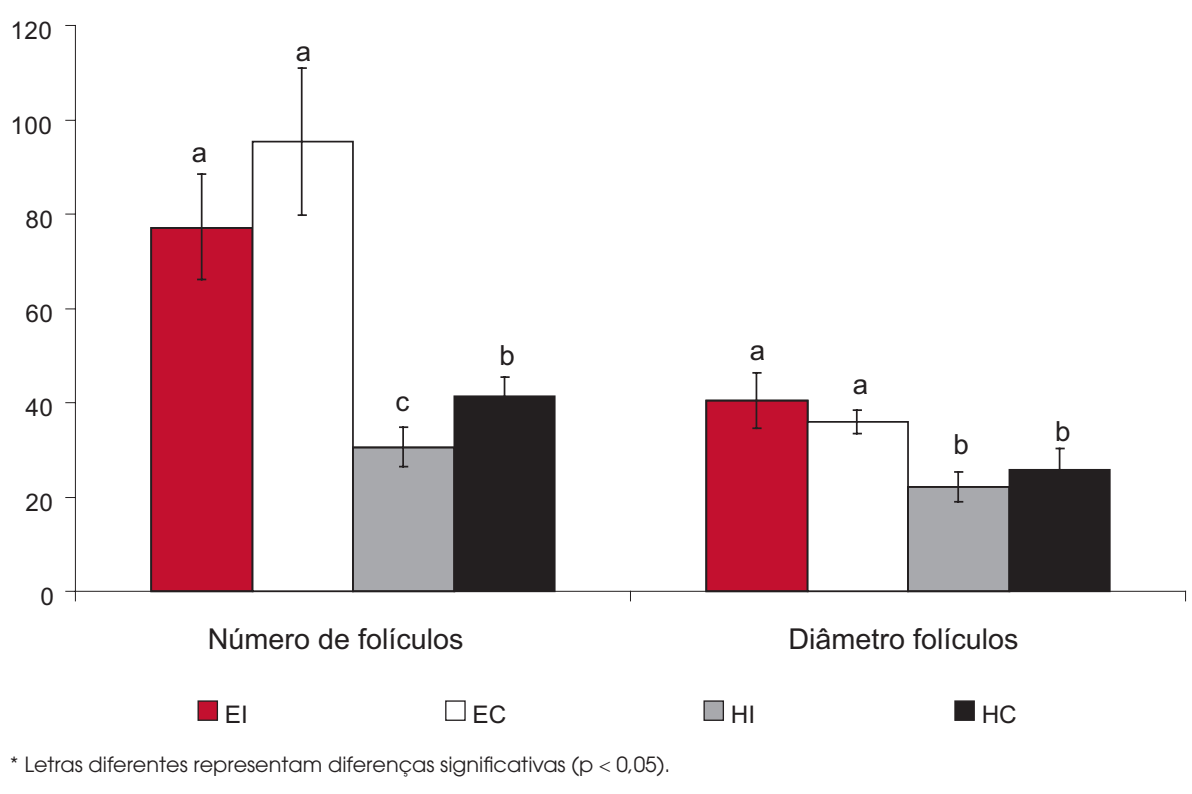

Figura 4. Número e diâmetro médio de folículos linfóides (média \pm SD) do baço de ratas adultas eutireóideas ovariectomizadas (EO), eutireóideas não-ovariectomizadas (El), hipotireóideas ovariectomizadas $(\mathrm{HO})$ e hipotireóideas não-ovariectomizadas $(\mathrm{HI})$

Os índices apoptóticos e a expressão de caspase 3 foram superiores nas células do baço de ratas dos grupos hipotireóideos em comparação ao grupo-controle (Figuras 5 e 6). Mas, notavelmente a ovariectomia mi- nimizou o aumento do índice apoptótico e da expressão de caspase 3 no baço de ratas hipotireóideas. Não houve diferença na expressão de CDC47 entre os grupos hipotireóideos e controle (Figura 5).

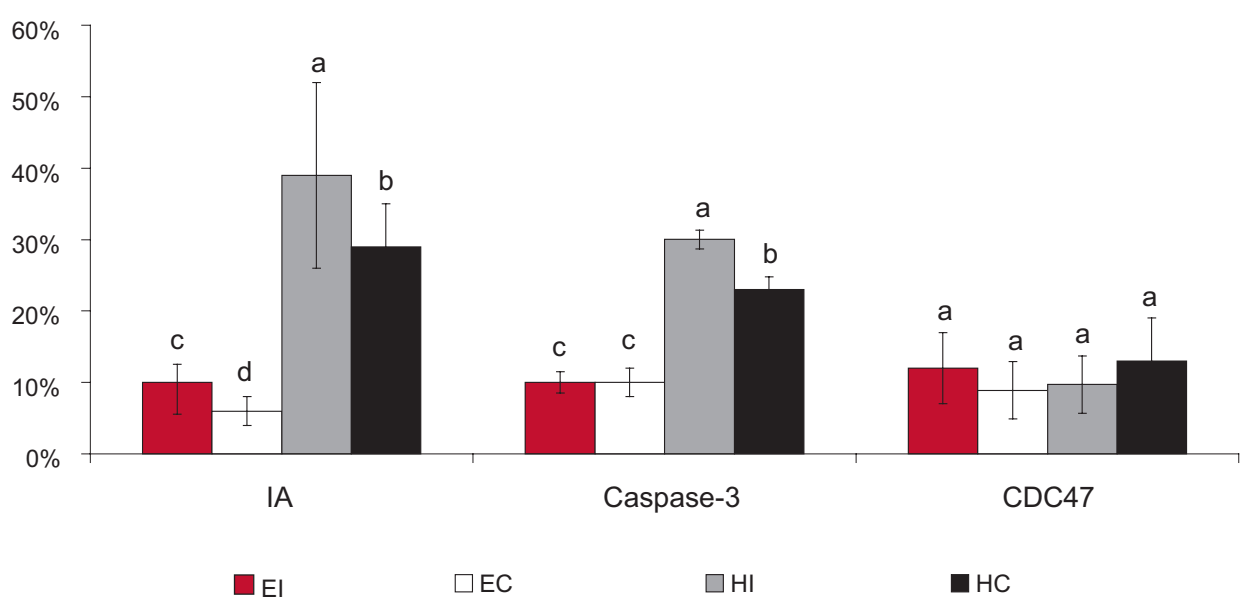

* Letras diferentes representam diferenças significativas $(p<0,05)$.

Figura 5. Porcentagem de células com características de apoptose em relação ao número total de células/campo (índice apoptótico) e porcentagem de células com expressão de caspase-3 e de CDC-47 em relação ao número total de células/campo (média \pm SD) em folículos linfóides do baço de ratas adultas eutireóideas ovariectomizadas (EO), eutireóideas não-ovariectomizadas (El), hipotireóideas ovariectomizadas $(\mathrm{HO})$ e hipotireóideas não-ovariectomizadas $(\mathrm{HI})$. 


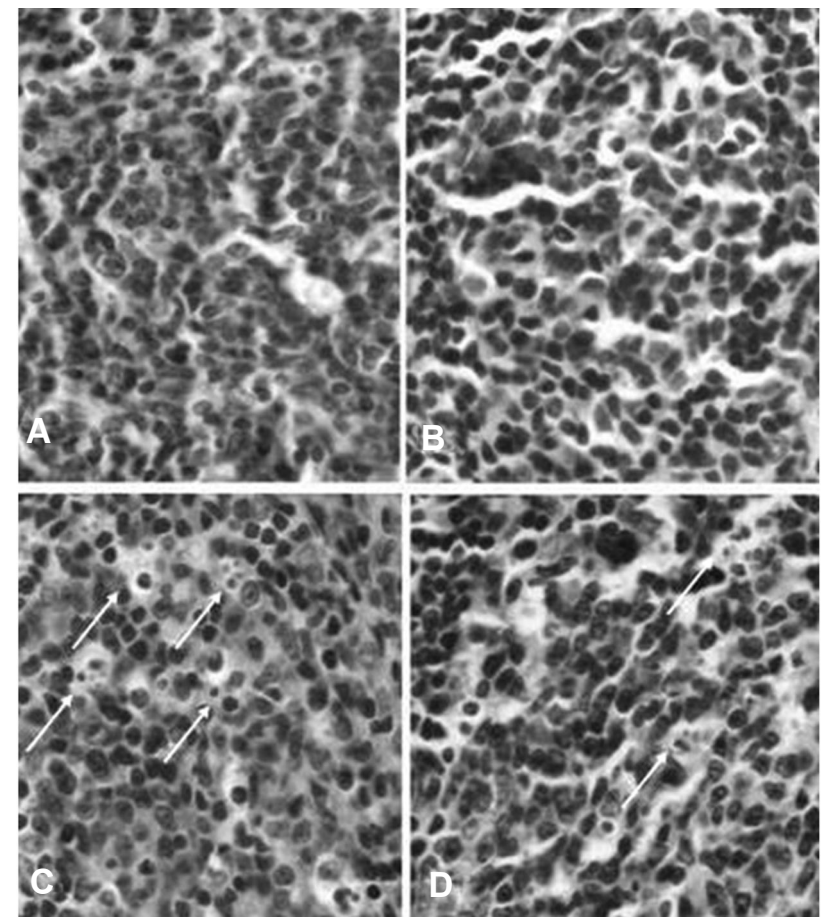

Figura 6. Fotomicrografia da polpa branca do baço de ratas adultas eutireóideas não-ovariectomizadas (A), eutireóideas ovariectomizadas (B), hipotireóideas não-ovariectomizadas (C) e hipotireóideas ovariectomizadas (D). Maior número de células apoptóticas (setas) no baço de ratas hipotireóideas não-ovariectomizadas em comparação aos demais grupos. Hematoxilina-eosina, 250x.

O grupo ovariectomizado sem hipotireoidismo apresentou hiperplasia de polpa branca. A porcentagem de polpa branca neste grupo foi significativamente superior a dos grupos-controle e hipotireóideo não-ovariectomizado e semelhante ao grupo hipotireóideo ovariectomizado (Figura 3). Os centros germinativos apresentavam células ora com núcleo vesiculoso e citoplasma abundante, ora menores com citoplasma escasso e núcleo condensado semelhante ao controle. Em algumas áreas observou-se confluência dos folículos, mas não houve diferença significativa na expressão de CDC47 e de caspase 3 entre o grupo eutireóideo ovariectomizado e o controle. No entanto, o índice apoptótico foi significativamente menor no grupo eutireóideo ovariectomizado em comparação ao controle (Figura 5).

\section{DISCUSSÃo}

As ratas deste estudo tratadas com PTU apresentaram hipotireoidismo caracterizado não somente por redução significativa dos valores plasmáticos de tiroxina li- vre, como também por letargia e alterações cutâneas representadas por hiperceratose e hipotriquia (4).

A escolha da razão peso do baço/peso corporal foi importante para evitar que as oscilações de peso corporal dentro de determinado grupo e entre grupos mascarassem as alterações.

Além das características celulares de apoptose que permitiram determinar o índice apoptótico, a expressão imunohistoquímica de caspase 3 tem sido utilizada para determinação das células em apoptose. As caspases pertencem à família de proteases aspartato cisteína específica, cuja ativação é o evento principal e irreversível do processo de apoptose (19). O processo se inicia pela ativação da caspase 8 , que pode ativar diretamente a caspase 3 , além de desencadear a liberação do citocromo $\mathrm{c}$ da mitocôndria que, por sua vez, ativa a caspase 9 e a caspase 3. A liberação do citocromo resulta a alteração do potencial de membrana com conseqüente abertura de poros. Este evento é ativado por vários compostos químicos, incluindo hormônios tireoidianos (20). Esta cascata de ativação resulta a liberação de endonucleases que provocam a fragmentação do DNA (21).

As ratas ovariectomizadas apresentaram maior porcentagem de polpa branca em relação aos demais constituintes do baço. Esse resultado ocorreu em virtude do aumento do número de folículos linfóides em comparação ao grupo-controle. Mas, o aumento da polpa branca foi acompanhado por redução da porcentagem de polpa vermelha, o que fez que a razão peso do baço/peso corpóreo não fosse significativamente maior em comparação ao grupo-controle. Além disso, as ratas eutireóideas ovariectomizadas eram mais pesadas em comparação às ratas eutireóideas não-ovariectomizadas, o que também contribuiu para não haver aumento da razão peso do baço/peso corporal. Os aumentos do número de linfócitos foram observados no timo, no baço e no linfonodo de ratos após castração (14) e, ao contrário dos resultados deste trabalho, foi evidenciado aumento do peso do baço em animais pré-púberes castrados (14). Postula-se que o aumento do número de linfócitos $\mathrm{B}$ no baço de animais castrados seja conseqüente ao estímulo à linfopoese B na medula óssea (14). No presente estudo, foi claramente demonstrado que na castração o aumento da celularidade da polpa branca não se deve ao aumento da taxa de proliferação representada pela expressão de CDC-47, mas pode ter sido decorrente da redução da taxa de apoptose, já que houve diferença entre o grupo ovariectomizado e o grupo-controle em relação ao índice apoptótico (Figura 5). 
Ao contrário da deficiência dos esteróides sexuais, altas concentrações de hormônios sexuais alteram a celularidade e a arquitetura tímica por induzir apoptose em timócitos (13). Além disso, estudos in vitro apontam o estradiol como estimulador de apoptose de linfócitos via supressão de $\mathrm{Bcl}-2$ e ciclina $\mathrm{A}$. O aumento da porcentagem de polpa branca no grupo eutireóideo ovariectomizado já era esperado, pois a ausência dos esteróides sexuais resulta aumento do número de linfócitos imaturos no timo, com conseqüente aumento periférico das células T e B (14). Entretanto, nessas mesmas ratas não se observou linfocitose periférica nos animais castrados (5). Os efeitos da ovariectomia na proliferação e na apoptose celular no baço de animais ovariectomizados ainda não haviam sido demonstrados.

Em comparação ao grupo-controle, a redução do peso do baço das ratas hipotireóideas foi decorrente da redução do número e do diâmetro de folículos linfóides por conseqüência do aumento da apoptose representada pelo índice apoptótico e pela expressão de caspase 3 . No entanto, a ovariectomia minimizou a apoptose no baço das ratas hipotireóideas e aumentou o número de folículos linfóides, provavelmente pelo efeito antagônico entre a deficiência dos hormônios tireoidianos e sexuais que deve ser mais investigado.

Os hormônios tireoidianos apresentam efeito importante nos processos de proliferação e apoptose. Estudos in vitro e in vivo demonstraram, simultaneamente, que T3 induz a proliferação e a apoptose (22). Pesquisas também demonstraram que a triidotironina está envolvida na morfogênese de anfíbios por estimular a proliferação e a apoptose celular (23). O tratamento com T3 em lobos ópticos de embriões de galinha promoveu a manutenção da homeostase entre apoptose e proliferação celular (24). Porém, no presente estudo, a supremacia da apoptose diante da proliferação celular no hipotireoidismo foi responsável pela redução da polpa branca esplênica com subseqüente redução do peso do órgão. A polpa branca é constituída por linfócitos e plasmócitos responsáveis pela resposta celular e humoral, respectivamente. Merece ser investigado se as alterações evidenciadas na polpa branca de ratas hipotireóideas poderiam comprometer as defesas imunes do animal diante de estímulo antigênico.

A identificação de núcleos com expressão de CDC47 é utilizada para a determinação das células que estejam em duplicação (25) e, por isso, foi utilizada para determinar a taxa de proliferação celular neste estudo. Nem o hipotireoidismo nem a ovariectomia alteraram a taxa de proliferação das células esplênicas de ratas adultas. $\mathrm{O}$ mecanismo de ação dos hormônios tireoidianos no ciclo celular ainda é bastante controverso e parece variar conforme a dose do hormônio, com o tipo celular, com o estágio de diferenciação da célula e com o tipo de ensaio in vivo ou in vitro. Em concentrações fisiológicas, os hormônios tireoidianos estimulam, in vivo, a síntese de DNA em hepatócitos, por aumentarem os níveis de ciclina $\mathrm{Dl}$ e cdk 4, que controlam a fase Gl e também estimulam a atividade de proteínas, como o complexo ciclina $\mathrm{E} / \mathrm{A}$ - cdk, que estão envolvidos na progressão da fase Gl para a fase $S$ (26). Por outro lado, o tratamento, in vitro, de hepatócitos com hormônios tireoidianos ativa enzimas inibitórias do estímulo na fase $S$ do ciclo celular, por reprimir a atividade da ciclina - cdk2 (26). No presente estudo, o hipotireoidismo causou desequilíbrio entre a taxa de proliferação e apoptose do baço de ratas adultas, com supremacia da apoptose.

\section{CONCLUSÃo}

Com base nos resultados, conclui-se que o hipotireoidismo reduz o peso do baço de ratas adultas por causar redução do número e do diâmetro de folículos linfóides e por aumentar a apoptose celular; a ovariectomia minimiza a apoptose no baço das ratas hipotireóideas e aumenta o número de folículos linfóides, provavelmente pelo efeito antagônico entre o hipotireoidismo e o hipogonadismo; e que o hipotireoidismo e a ovariectomia não alteram a taxa de proliferação celular no baço de ratas adultas.

Agradecimentos: À Fundação de Amparo a Pesquisa de Minas Gerais (Fapemig) pelo apoio financeiro, ao Conselho Nacional de Desenvolvimento Científico e Tecnológico (CNPq) pela concessão de bolsas e à Coordenação de Aperfeiçoamento de Pessoal de Nível Superior (Capes) (edital pró-equipamen-

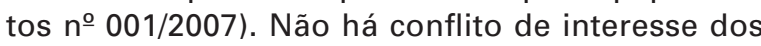
autores.

\section{REFERÊNCIAS}

1. Mazzaferri EL. Evaluation and management of common thyroid disorders in women. Am J Obstet Gynecol. 1997;176:509-14.

2. Serakides R, Nunes VA, Nascimento EF, Ribeiro AFC, Zibaoui HM, Silva CM. Hipogonadismo e função tireoidiana em ratas hipertireóideas e eutireóideas. Arq Bras Med Vet Zoot. 2000;52:571-8.

3. Serakides R, Nunes VA, Nascimento EF, Silva CM, Ribeiro AFC. Relação tireóide-gônadas e níveis plasmáticos de fósforo, cál- 
cio e fosfatase alcalina em ratas. Arq Bras Med Vet Zoot. 2000;52:579-85.

4. Ferreira E, Serakides R, Nunes VA, Gomes MG, Silva CM, Ocarino NM, et al. Morfologia e histoquímica da pele de ratas hipotireóideas castradas e não castradas. Arq Bras Med Vet Zoot. 2003;55:51-60.

5. Gomes MG, Serakides R, Nunes VA, Silva CM, Carneiro RA, Ocarino NM. Perfil hematológico de ratas adultas hipotireóideas castradas e não castradas. Arq Bras Endocrinol Metab. 2004;48:294-8.

6. Montecino-Rodriguez E, Clark R, Johnson A, Collins L, Dorshkind K. Defective B cell development in Snell dwarf (dw/dw) mice can corrected by thyroxine treatment. J Immunol. 1996;157:3334-40.

7. Montecino-Rodriguez E, Clark R, Powell-Braxton L, Dorshkind K. Primary B cell development is impaired in mice with defects of the pituitary/thyroid axis. J Immunol.1997;159:2712-9.

8. Foster MP, Montecino-Rodriguez E, Dorshkind K. Proliferation of bone marrow pro-B cells is dependent on stimulation by the pituitary/thyroid axis. J Immunol. 1999;163:5883-90.

9. Holdstock G, Chastenay B, Krawitt EL. Effects of testosterone, oestradiol and progesterone on immune regulation. Clin Exp Immunol. 1982;47:449-56.

10. McKenzie CE, Berczi I. Oestrogen dependent suppression of mitogen response in rat lymphocytes. Acta Endocrinol (Copenh). 1987;116:200-4

11. Stefano GB, Cadet $P$, Breton $C$, Goumon $Y$, Prevot $V$, Dessaint $\mathrm{JP}$, et al. Estradiol-stimulated nitric oxide release in human granulocytes is dependent on intracellular calcium transients: evidence of a cell surface estrogen receptor. Blood. 2000:95:3951-8.

12. Jenkins JK, Suwannaroj S, Elbourne KB. 17-b-Estradiol alters Jurkat lymphocyte cell cycling and induces apoptosis through suppression of $\mathrm{Bcl}-2$ and cyclin A. Int Immunophar. 2001;1:1897-911.

13. McMurray RW, Wilson JG, Bigler L, Xiang L, Lagoo A. Progesterone inhibits glucocorticoid-induced murine thymocyte apoptosis. Int Immunophar. 2000;22:955-65.

14. Windinill KF, Lee VWK. Effects of castration on lymphocytes of thymus, spleen and lymph nodes. Tissue Cell. 1998;30:104-11.

15. Moro L, Martins AS, Alves CM, Santos FGA, Puerto HL, Vasconcelos AC. Apoptosis in the cerebellum of dogs with distemper. J Vet Med Sci. 2003;50:221-5.

16. Caliari MV. Princípios de morfometria digital: KS 300 para iniciantes. Belo Horizonte: UFMG; 1997.
17. Kerr NF, Wyllie AH, Currie AR. Apoptosis: a base biological phenomenon with wide- ranging implications in tissue kinetics. Br J Cancer. 1972;26:239-57.

18. Sampaio IBM. Estatística aplicada à experimentação animal. Belo Horizonte: FEP/MVZ; 1998.

19. Marti A, Graber H, Lazar H, Ritter PM, Baltzer A, Srinivasan A, et al. Caspases: decoders of apoptotic signals during mammary involution. Caspase activation during involution. Adv Exp Med Biol. 2000;480:195-201.

20. Hermesh O, Kaldern B, Berman B, Bar-Tana J. Mitochondrial protonophoric activity induced by a thyromimetic fatty acid analogue. Biochim Biophys Acta. 2000;1457:166-74.

21. Widtak P. The DFF40/CAD endonuclease and its role in apoptosis. Acta Biochim Pol. 2000;47:1037-44.

22. Su $Y$, Shi $Y$, Stolow MA, Shi YB. Thyroid hormone induces apoptosis in primary cell cultures of tadpole intestine: cell type specificity and effects of extracellular matrix. J Cell Biol. 1997;139:1533-43.

23. Shi YB, Sachs LM, Jones $P$, Li Q, Ishizuya-Oka A. Thyroid hormone regulation of Xenopus laevis metamorphosis: functions of thyroid hormone receptors and roles of extracellular matrix remodeling. Wound Repair Regen. 1998;4:314-22.

24. Ghorbel M, Seugnet I, Ableitner AM, Hassan A, Demeneix BA. T3 treatment increases mitosis, then bax expression and apoptosis in the optic lobe of the chick embryo. Neurosci Lett. 1997;231:127-30.

25. Dalton S, Whitbread L. Cell cycle-regulated nuclear import and export of Cdc47, a protein essential for initiation of DNA replication in budding yeast. Proc Natl Acad Sci U S A. 1995;92:2514-8.

26. Alisi A, Spagnuolo S, Napoletano S, Spaziani S, Leoni S. Thyroid hormones regulate DNA-synthesis and cell-cycle proteins by activation of PKC $\alpha$ and p42/44 MAPK in chick embryo hepatocytes. J Cell Physiol. 2004;201:259-65.

Endereço para correspondência:

Rogéria Serakides

Setor de Patologia do Departamento de Clínica e Cirurgia Veterinárias da UFMG

Av. Pres. Antônio Carlos, 6.627 - Caixa Postal 567

31270-901 Belo Horizonte, MG

E-mail: serakide@dedalus.lcc.ufmg.br 